\title{
Remotely-sensed vegetation greening along a restoration gradient of a tropical forest, Kibale National Park, Uganda
}

\author{
Anu Valtonen ${ }^{1}$, Eveliina Korkiatupa ${ }^{1}$, Sille Holm ${ }^{1}$, Geoffrey Malinga ${ }^{1}$, and Ryosuke \\ Nakadai $^{2}$ \\ ${ }^{1}$ University of Eastern Finland \\ ${ }^{2}$ The University of Tokyo
}

April 9, 2021

\begin{abstract}
Restoration has now emerged as a global priority, with international initiatives such as the "UN Decade on Ecosystem Restoration (2021-2030)". To fulfil the large-scale global restoration ambitions, an essential step is the monitoring of vegetation recovery after restoration interventions. The aim of this study was to evaluate the utility of remotely-sensed vegetation indices, Normalized Difference Vegetation Index (NDVI) and Enhanced Vegetation Index (EVI), to monitor the rate of forest regeneration across a tropical forest restoration project area in Kibale National Park, Uganda. As a result, we observed non-linear patterns in NDVI and EVI across the first 25 years of recovery. Both NDVI and EVI increase for the first 10 years of forest regeneration. This "greening" phase could be used as the indicator of successful onset of forest recovery. In particular, the decline of elephant grass, which suppresses the natural regeneration of trees in our area, can be detected as an increase in NDVI. Primary forests differed from the 25-year-old regenerating forests based on the unique combination of low mean and low seasonal variation in EVI. Our results, therefore, suggest that the long-term success of forest restoration could be monitored by evaluating how closely the combination of mean, and degree of seasonal variation in EVI, resembles that observed in the primary forest.
\end{abstract}

\section{Hosted file}

valtonen_etal_main_text.pdf available at https://authorea.com/users/406748/articles/517296remotely-sensed-vegetation-greening-along-a-restoration-gradient-of-a-tropical-forestkibale-national-park-uganda 


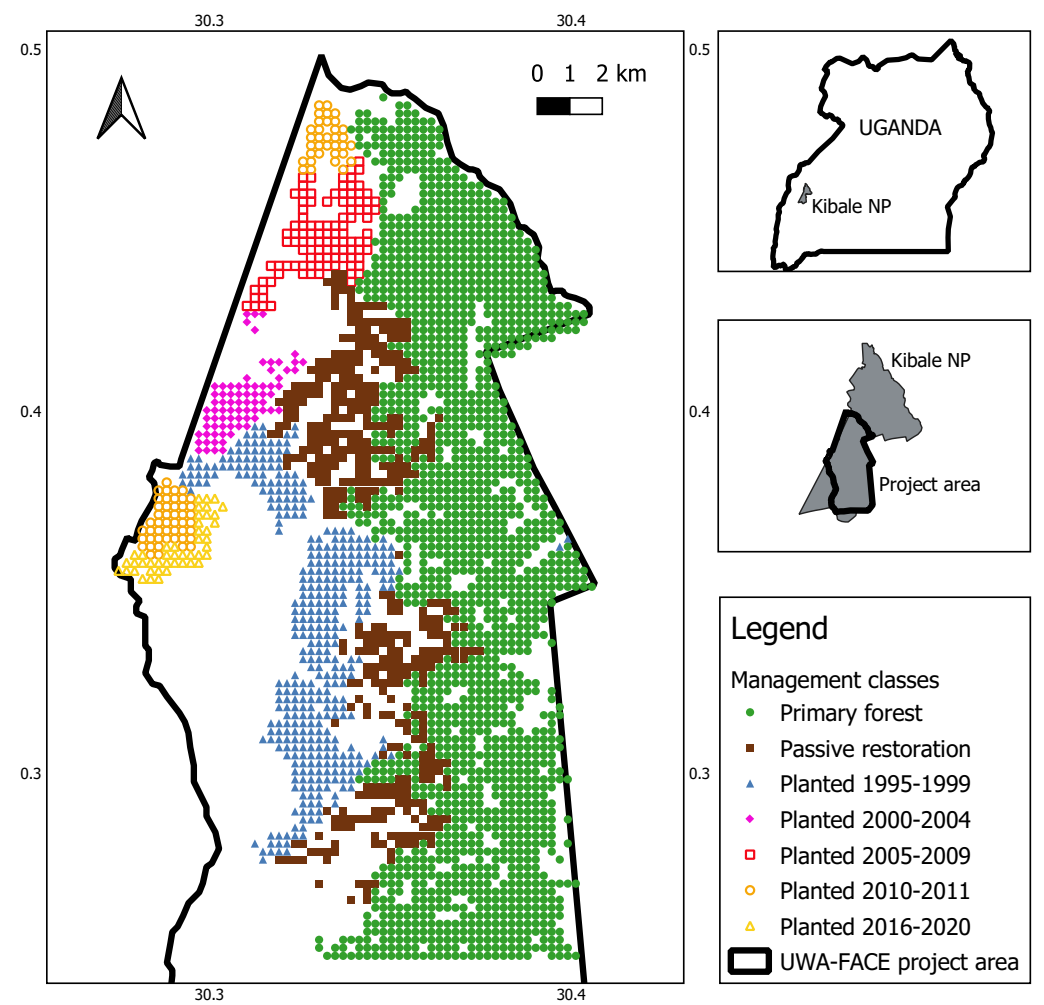



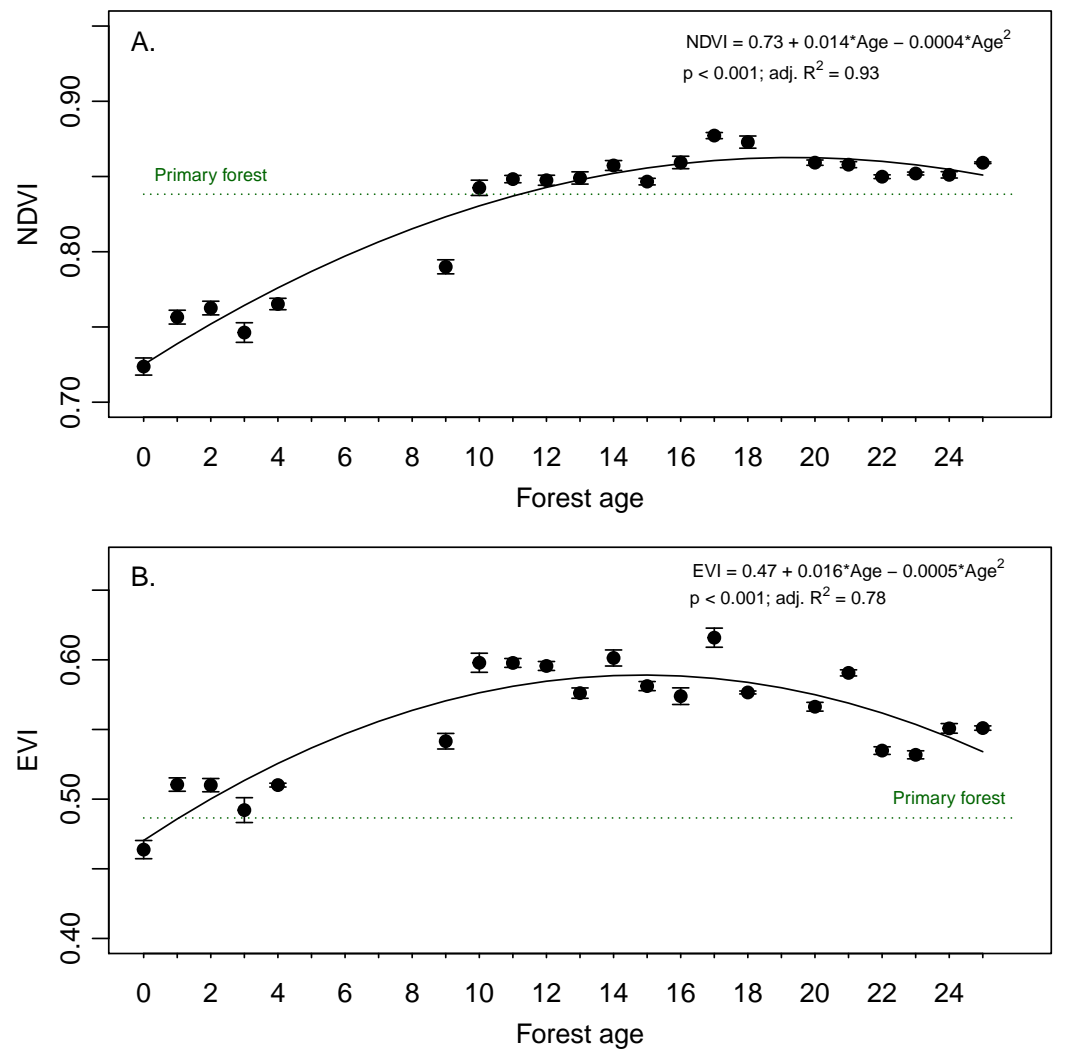

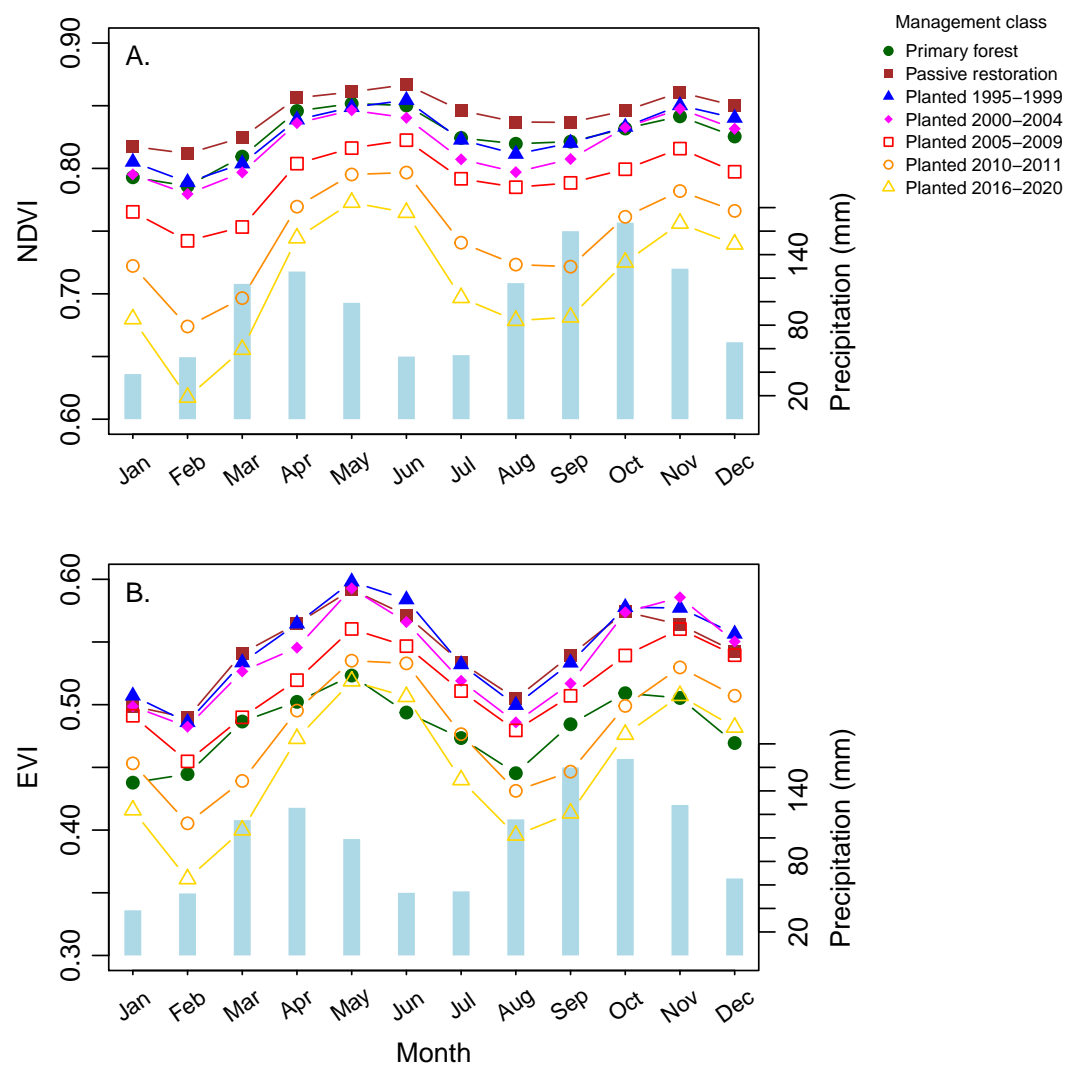


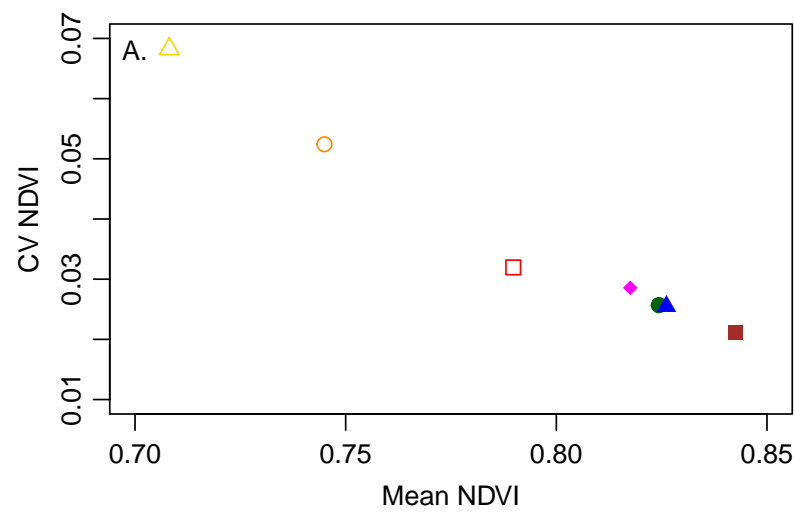

Management class

- Primary forest

- Passive restoration

- Planted 1995-1999

- Planted 2000-2004

Planted 2005-2009

Planted 2010-2011

Planted 2016-2020

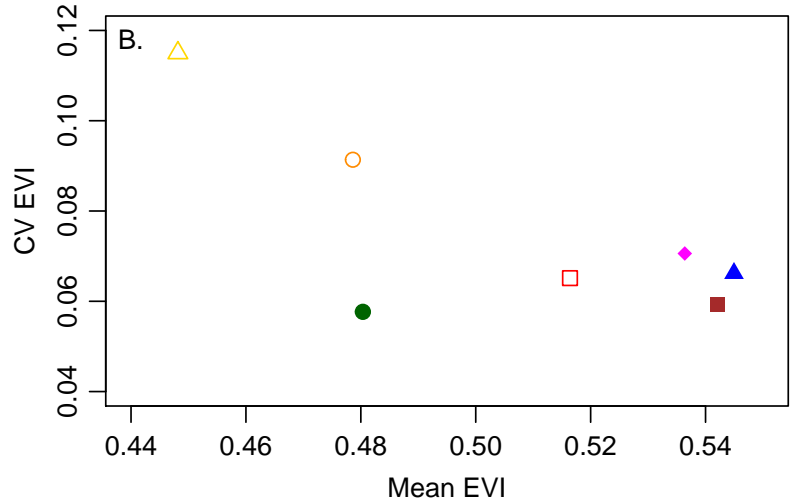



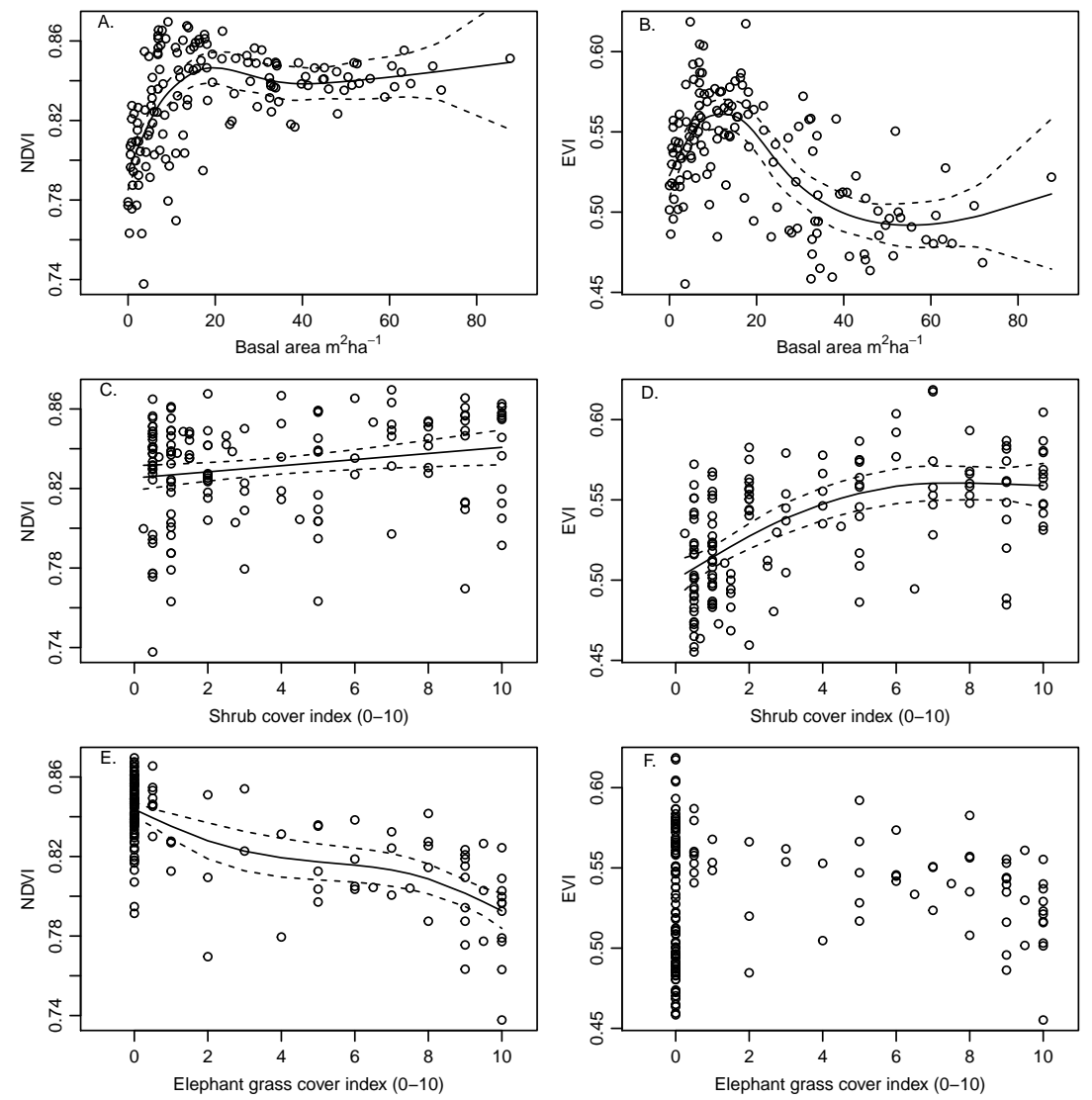